\section{Parental smoking at home and height of children}

It is recognised that smoking by mothers during pregnancy is associated with low birth weight ${ }^{1}$ and that the subsequent physical growth of children born to these mothers is impaired. ${ }^{2}$ Babies with parents who smoke also have more respiratory illness in the first year of life. ${ }^{3}$ Data from a study in Cleveland of 539 6- and 7-year-old children suggested an association between short stature in the child and number of smokers in the home. We tested this hypothesis using data from the National Study of Health and Growth, which provided a large sample of primary schoolchildren.

\section{Methods and results}

In the National Study of Health and Growth the heights of children in 28 study areas in England and Scotland were measured. Each child's parents gave information on the father's occupation, parents' reported height, number of siblings of the child, and child's birth weight. In 1977 we also included questions on the number of people smoking at least five cigarettes a day at home and the child's respiratory symptoms. The study design and measurement technique have been described elsewhere. ${ }^{4}$ The children were divided into three groups according to whether there were no smokers, one smoker, or two or more smokers in the home. In an analysis of variance we tested for a trend of height across the three smoking categories and allowed for variables that might be related to both smoking behaviour and stature. Standardised height by age, sex, and country of residence was obtained for each child as the difference between his height and the mean height in his group divided by the standard deviation for that population. ${ }^{5}$

A strong inverse association was found between height and number of smokers at home $(p<0.001$ in England and $p<0.01$ in Scotland). Children with one smoker at home had an intermediate mean height compared with the two other groups in both countries (figure). After adjustment for the

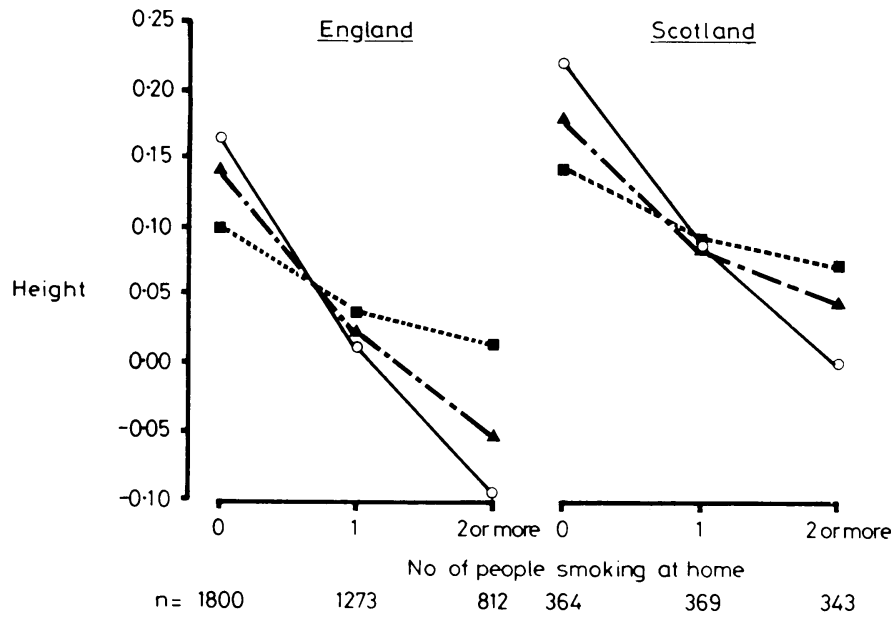

Mean standardised height of children by number of people smoking five or more cigarettes a day at home.

$0-0=$ Unadjusted. $\Delta--\Delta-$ Adjusted for child's birth weight. - - - Adjusted for child's birth weight, number of siblings, father's social class, and parents' height.

child's birth weight to allow for the mother's smoking during pregnancy the trend was still significant in England $(p<0.001)$ but borderline in Scotland $(p<0 \cdot 1)$. After further adjustments for the father's social class, the mother's and father's heights, and the number of siblings a significant trend remained in the English sample $(p=0.01)$ and a non-significant trend in the Scottish sample (the Scottish sample was one-third the size of the English). A similar analysis by sex showed a significant trend for boys but not for girls in England after all other independent variables had been allowed for. In Scotland the trend was observed only in girls $(p<0.05)$. The number of respiratory symptoms in the previous 12 months did not explain the association between height and smoking behaviour at home.

\section{Comment}

The association between smokers at home and children's height cannot be explained by smoking in pregnancy because adjusting for each child's birth weight did not eliminate differences in height between the groups. The significant gradient found in England after adjustment for the parents' height, number of siblings, and father's social class is further evidence that the association is due to passive smoking. In Scotland a trend of the same magnitude as in England was not significant.

We investigated whether respiratory symptoms in childhood were a necessary step between passive smoking and a child's impaired growth. Our analysis indicated that this is unlikely. Respiratory symptoms before the child entered school, however, may have played a part.

Passive smoking at home, therefore, seems to affect the growth of children. The maximum difference in mean height between groups was about $1 \mathrm{~cm}$. This was the value reported by Butler and Goldstein ${ }^{2}$ in 7- and 11-year-old children whose mothers smoked during pregnancy.

We thank Professor W W Holland and our helpers in the study areas. This study is funded by the Department of Health and Social Security and the Scottish Home and Health Department.

${ }^{1}$ Butler NR, Goldstein H, Ross EM. Cigarette smoking in pregnancy: its influence on birth weight and perinatal mortality. Br Med $\mathcal{F} 1972$;ii 127-30.

${ }^{2}$ Butler NR, Goldstein H. Smoking in pregnancy and subsequent child development. Br Med f 1973;iv:573-5.

${ }^{3}$ Colley JRT, Holland WW, Corkhill RT. Influence of passive smoking and parental phlegm on pneumonia and bronchitis in early childhood. Lancet 1974 ;ii:1031-4.

4 Rona RJ, Altman DG. National Study of Health and Growth: standards of attained height, weight and triceps skinfold in English children 5 to 11 years old. Ann Hum Biol 1977;4:501-23.

${ }^{5}$ Rona RJ, Florey CduV. National Study of Health and Growth: respiratory symptoms and height in primary schoolchildren. Int $\mathcal{f}$ Epidemiol 1980 9:35-43.

(Accepted 27 July 1981)

Department of Community Medicine, St Thomas's Hospital Medical School, London SE1

R J RONA, MED-CIR, PHD, lecturer

$C$ DU V FLOREY, MD, FFCM, professor

G C CLARKE, statistical assistant

S CHINN, MA, senior lecturer in medical statistics

\section{Human papovavirus isolated from urine of a child with acute tonsillitis}

The human papovavirus $\mathrm{BK}$ has been isolated exclusively from people who were immunologically impaired ${ }^{1}$ and from pregnant women. ${ }^{2}$ In these cases the presence of infective virus seemed to result from virus reactivation as shown by the presence of $B K$ virus antibodies before virus excretion. Isolation of $\mathrm{BK}$ virus has not been reported during the primary infection of immunologically competent individuals even though antibody surveys have shown a $60-80 \%$ prevalence of $\mathrm{BK}$ virus antibodies in adults. Antibodies to $\mathrm{BK}$ virus usually occur in early childhood. ${ }^{3}$ Serological studies have suggested a possible association between primary infection with $\mathrm{BK}$ virus and acute upper respiratory tract disease. ${ }^{5}$ We report the isolation of a human papovavirus from urine of an immunologically competent child with acute tonsillitis.

\section{Case report}

On 16 October 1980 a 2-year-old mentally retarded boy was admitted to the department of paediatrics of the university clinic with dyspnoea and high fever. Physical examination showed nasal discharge, swollen inflamed tonsils, enlarged cervical lymph nodes, and conjunctival irritation. His medical history included several hospital admissions for acute respiratory and gastrointestinal illnesses. Laboratory investigations showed normal biochemical values for blood and urine, normal serum immunoglobulin concentrations, and normal lymphocyte functions. Throat cultures were negative for haemolytic streptococci. Bacterial cultures of urine and faeces chowed normal flora. Within 11 days he had recovered from the tonsillitis, and he left the hospital on 27 October in good health. On the third day of the illness a throat swab and urine sample were collected for virological examination and inoculated into cultures of primary thyroid cells. 